\title{
Semiotics of Business Signage: How typography is used in impoverished and deprived areas of New Zealand
}

\author{
David Sinfield, Auckland University of Technology, New Zealand
}

\begin{abstract}
There is no disputing the fact that Auckland Central Business District (C.B.D) is well positioned within the multinational corporate world community. Walking through the streets of Auckland's C.B.D one could be anywhere throughout the world as the corporate branding of the world famous companies within the C.B.D are indicative to each other regardless of the country.

I work in Auckland's C.B.D area and on my to work each morning I travel through one of New Zealand poorest areas of NZ, Otara, South Auckland, which has a large percentage of Pacifica ${ }^{1}$ residents and has one of the highest unemployment figures in NZ. It is travelling through this town on a daily bases that made me notice how the local businesses are designing and displaying their signage within this small community town and how it has become a synonymous branding, not on a corporate level but more of a community level and one that sits comfortably with the local people.

The aim in this paper is to document and examine examples of signage from these poor areas of South Auckland and to point out the subtleties or difference's from these; in most cases hand produced signage, which is functional but lacks in the traditional form of typographical design, which is well documented in the corporate world.

This research project will outline some of the findings that I have encountered on my journey and how important it is to maintain a sense of community within areas such as these.
\end{abstract}

Keywords: Decaying Signage, Typography, Semiotics,

\section{Preamble_-Decaying Signage}

$\mathrm{E}$ roding signage has proven to be a powerful metaphor in storytelling. F. Scott Fitzgerald used it evocatively in The Great Gatsby (1925). In his novel, destiny (or God) metaphorically watched the world's moral erosion through the bespectacled eyes of Doctor T. J. Eckleburg. These stared out from a fading advertising billboard situated in the valley of ashes.

The eroding sign is an evocative image (Romany, 2012). It may be seen as a marker of an original purpose (advertising), but also a marker of time. It not only signifies place (Clark \& Bell, 1994), memorial (Ings, 2001) and social class, but it also becomes woven with our personal narratives of place. These narratives Olney suggests, provide "contexts and patterns through which we can read, understand, re-realize, and transmit our experience” (1998, p.315). Billings (2009, p.2) argues that objects like billboards "do not simply exist in a crude material sense but rather live out complex selfperceived narratives".

As recently as the 1980s storefronts, murals, banners, barn signs, billboards, and even street signs were all hand-lettered with brush and paint (Levine \& Macon, 2012). But, like many skilled trades, the

1. Pacific people in New Zealand are represented by at least 13 distinct languages and cultural groups. The Pacific population includes people born in the Pacific Islands and in New Zealand. The many Pacific ethnicities are represented primarily by Samoan, Cook Islands, Tongan, Niuean, Fijian and Tokelauan groups, with smaller numbers from Tuvalu, Kiribati, Papua New Guinea, Vanuatu, the Solomon Islands and the small island states of Micronesia. 
sign industry has been quicker and cheaper technological 'solutions'. The skill and artistic brushstrokes of the sign writer carried not only unique approaches to design but also expressed richly evocative reflections on time. Many of these handwritten commercial signs have not been retouched in years. They now constitute a now anachronistic voice of the sign writer whose brushes; rulers and gilding equipment have faded from the industry (Cox, 2014). The irregularities of once fashionable typefaces do not have the impeccable currency of a modern digital font, with its perfect tolerance and genericised application. Painted advertising often seen on the side of buildings sometimes more than four stories high have now become pieces of flaking fragments. They allude to an erosion of time and craft.

In cities like London and New York there has been a growing trend to document these fast disappearing works (Cox, 2014; Jump, 2011). This is because these signs tell stories of a city's past that weave together unique histories, cultures, environments, commerce, places and people from a complex composite social narrative.

Paintings incorporating words and phrases were popularized by artists such as Ed Rucher (1970). His representations of Hollywood logos, stylized gas stations, and archetypal landscapes distilled the imagery of popular culture into a language of cinematic and typographical codes that became as accessible as they were profound. His sentences and phrases evoked an American vernacular, and drew attention to a particular experience, or recalled the excesses of Hollywood culture. More recently, artists like Jay Shells (2013) have engaged in textual poaching of current street signs. He transforms these into Hip Hop quotes from songs that mention specific places. He then re-posts the signs in their mentioned locations as a means of engaging in a form of vernacular discourse.

Heavily eroded street signs from what is now called the most toxic town in America (Picher Oklahoma) have been documented by photographer Chris Brewer (2013). These signs provide an evocative commentary on the damaging toxicity of industrial environments. Brewer's work builds upon a growing corpus of photographic material that examines surfaces in decaying built environments (Romany, 2012; Loo, 2011).

Investigations have also been made into the impact of meteorological damage on public signage. Significant among these is Tom Varisco's (2008) Signs of New Orleans. This photographic portfolio documents signage and its context following the devastation wrought by hurricane Katrina in 2005.

\section{Signage Signifiers in the Community}

There is no disputing the fact that the Auckland Central Business District is indicative of multinational approaches to generalization. Walking through the streets one could be in any central business district anywhere in the World. As the corporate branding machine flexes its muscles and confidently replaces local identity with culturally non-descript aesthetics, it eats away at local businesses oblivious to community traditions and their graphic 'voices'.

Travelling through these areas one encounters an eerie feeling of déjà vu as the architecture and company signage are the same. From the positioning of the signage on a building, to the colour and materials used, there is little to trouble a seamless flow of corporate homogenisation. This hasn't happened by chance, but has been produced (in conscious detail) by graphic design agencies hired by branded corporations. What this ensures is a mineralisation of difference so the corporate brand can gain dominance over established cultural identities. This isn't only happening in business districts. It can also seen in towns and suburbs where local businesses are slowly squeezed out as rent increases force them to close or relocate. What have often been generationally owned small family businesses begin to make way for franchises and multinational chains. The general public are systematically seduced into shopping and buying goods from a select group of franchised companies. Choice is constrained so the consumer who buys inside their branded homogenised lifestyles (Levine \& Macon, 2012). Newly branded communities begin to lose character as ever-increasing profit margins dictate what commodities we consume. The cost of course, is a loss of local identity. This involves a replacement of local cultural signifiers with universalised brand identities.

\section{A Reflective Journey}

I teach graphic design at the Auckland University of Technology close to Auckland's C.B.D area. On my way to work each morning I travel through one of New Zealand's poorest areas, Otara in South Auckland. Otara has one of the highest unemployment figures in the country and one of the lowest 
family incomes in New Zealand ${ }^{2}$. The population comprises mainly Pacifica people from Tonga and Samoa (See Figures 1,2,3).

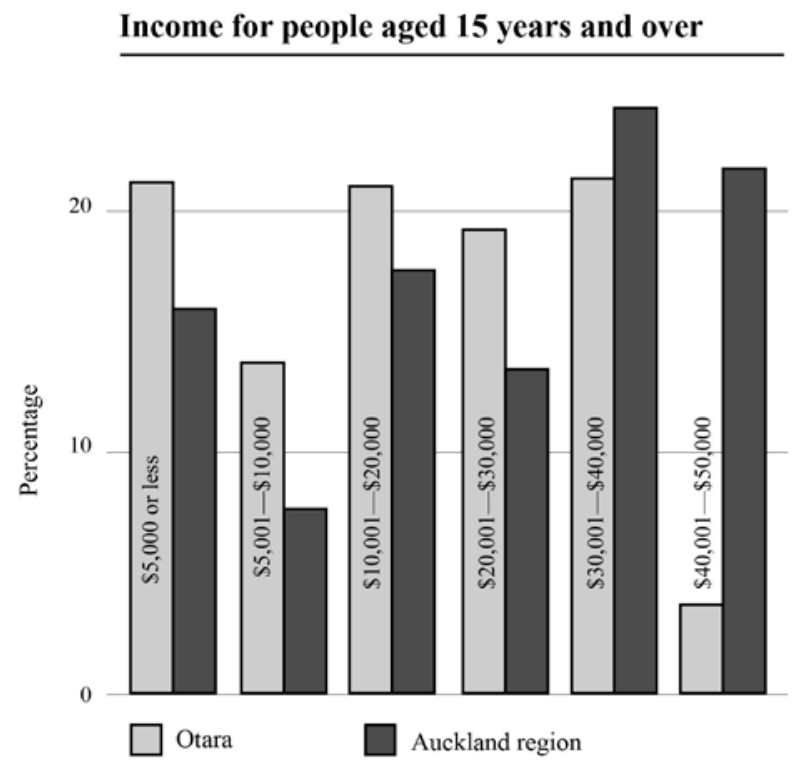

Figure 1: Income for people aged 15 years and over. Data adapted from government statistics, Sinfield 2013.

Auckland's C.B.D and Otara could not be more different. Although it is just a fifteen-minute car ride away, one could assume one has travelled across the boarder of another country. What is immediately evident is the high financial investment in Auckland's C.B.D area in contrast to Otara. Otara has however, preserved distinctive examples of a cultural vernacular. As I drive through the town I immediately notice local branding and signage that carries not only unique approaches to design but also the corrosive effects of time. Many of Otara's commercial signs have not been touched or repaired in years. As I drive through it's commercial district I notice how branding is indicative of a local 'voice'. A unique sense of community is revealed in distinctive typography ${ }^{3}$ treatments that draw from, and speak back to the 'street'. I would argue that a form of authentic exchange occurs as a consequence. The humour, pragmatism and personality of businesses emphasis uniqueness in contrast to the standardising and homogenising encountered in Auckland's C.B.D. It is clear to see that the ethnic groups of the poorer areas are very different to the ethnic groups within the C.B.D and this is equally reflected within the signage in these two areas.

2. Currently the only available statistics are from the 2006 New Zealand census. The unemployment rate in Otara was 21.2 percent, compared with neighbouring Manukau City at 10.1 percent and 7.5 percent for all of New Zealand. The most popular occupational group in Otara was Plant and Machine Operators and Assemblers (25.5 percent).

3. Typography is the art and technique of arranging pre-designed typefaces in order to make text legible and aesthetically pleasing. Modern typography can also be seen as a stand a-loan form of graphic design void of any additional images or graphic elements. 


\section{Ethnic groups in Otara, New Zealand}

\begin{tabular}{lr} 
Pacific peoples & $78.1 \%$ \\
\hline Mãori & $10.2 \%$ \\
\hline European & $8.7 \%$ \\
\hline Asian & $2.0 \%$ \\
\hline Other ethnicity & $0.8 \%$ \\
\hline Middle Eastern/Latin American/African & $0.2 \%$ \\
\hline
\end{tabular}

Figure 2. The information above shows the percentage breakdown of ethnic groups within Otara. Data adapted from government statistics, Sinfield 2013.

\section{Highest qualification for people aged 15 years and over}

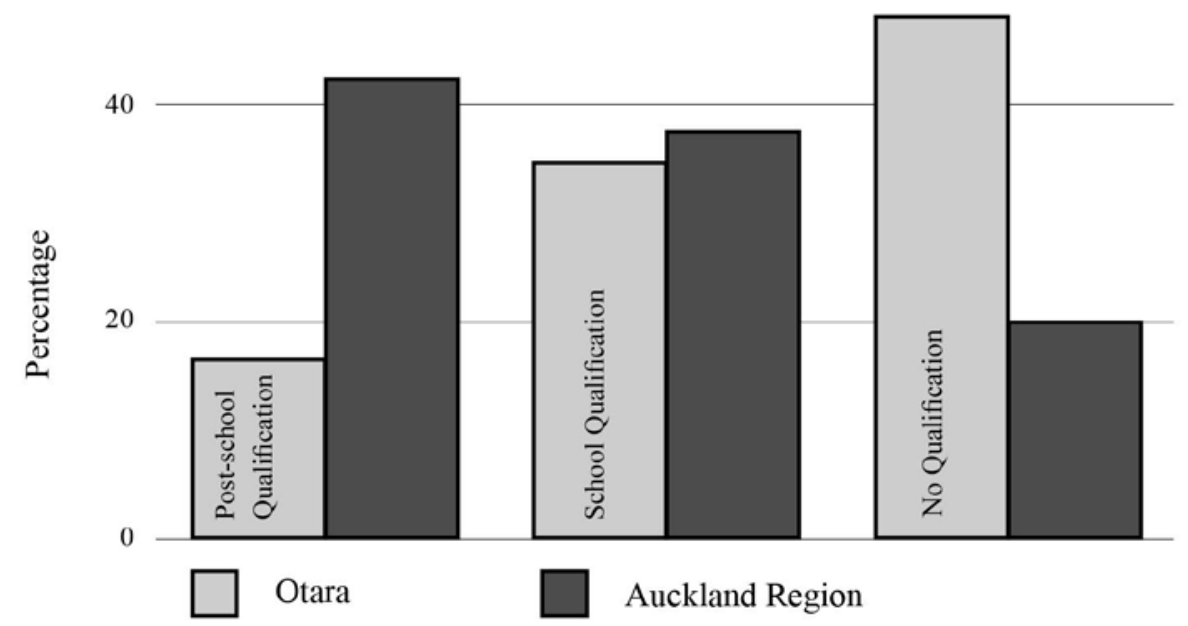

Figure 3. The information above shows people living in Otara with minimum or no qualifications. Data adapted from government statistics, Sinfield 2013.

\section{Typography and Signage}

As a graphic and typographical designer one is continually looking at visual content and analysing examples, be they good bad or indifferent. As a designer I am drawn to the sense of authenticity in these signs. I am interested in their typographical 'breaks with convention'. I am attracted to the impact of age on their meaning. Age (as wear and tear) is something scrupulously avoided in corporate 
branding, yet in these signs it operates as a signifier of performance; a 'belongingness' that forms part of an ongoing, joyous, vernacular of cultural uniqueness (Salin, 2001).

\section{The Cultural Politics of Typography}

Typography is often seen, as the subtle hero of graphic design, as good typography more often than not, will go unnoticed while bad examples will stand out. Yet ideas surrounding 'good' and 'bad' typographic design are culturally derived.

Salen (2001) notes that typographic treatments can operate as a form of cultural dominance. She suggests that typography operates as a "visual voice over, which constitutes a... symbolic environment, as well as the organic process by which a standardized voice is generalized across an entire range of cultural expression" (p.134). Thus faces like Cooper Black, Helvetica, Bell Gothic, Arial, Univers, Century School book, and Times New Roman have become ubiquitous voices to which we have grown accustomed in corporate signage. Salen suggests these faces are utopian and generic, "belonging nowhere, region less, without accent" (ibid.). In a mediated, global environment, she suggests they have no dialect and no affiliation to region and, as seemingly non-aligned; they are culturally superficial and stereotypical.

Typefaces like these operate as the dominant voice of the corporate world. They have established, regular leading ${ }^{4}$ and kerning ${ }^{5}$ that conform to Eurocentric conventions. Against them 'otherness' is demarcated. Thus the standardised conventions of their use Salen suggests mark "exclusionary distinctions between standard and non-standard 'speakers' (ibid.). Conversely, typographical features we encounter in the Otara signs are distinctively non-standardised (in fact their non-standardised nature is part of their vernacular). As a consequence, they are not stereotypical and they are clearly regionally located and expressive. They are the distinct 'voice' of the unique urban business culture inside which they function.

Travelling through Otara ${ }^{6}$ on a daily bases I notice how local businesses produced and display signs in a fascinating array of variations. These variations have not been produced by expensive signage machinery but have been produced by hand and more often than not a simple brush and a tin of pint. These include work produced by what would seem to be inexperienced people evident through fluency of their visual rendition to sign written boards that are the residues of a bygone age where hand lettering, gilding and illustration (Levine \& Macon 2012) were the marks of (normally local) craftsmen. The professional sign writer is a trade that is vanishing. It has been substituted by the robotic type laser cutter that produces print products from digital software.

\section{The Photographic Reflection}

This study photographically reflects upon examples of typography used in business signage in Otara. It uses images to speak to a fading vernacular. We read the marks of time and culture. We encounter the idiosyncratic and socio-economic as painted surfaces on wood. In comparatively depressed economic environment like Otara, small local business own displays their company names and the goods or services they are selling. They have often used a tin of available paint and scraps of old board. Otara is a comparatively poor working class suburb. Business owners are generally residents and a number of signs in this study represent generational family commitments to the area. These local business owners produce functioning signs for their businesses (this is to say they haven't employed a sign writer or design agency).

By comparison signage in the C.B.D has generally been computer generated and cut by a machine within a perfect tolerance. But these signs are void of any personal character, as they do not bear the physical marks of making. As Kepes (1994) notes, "each tool and each material has its own idiom of movement”. (p. 187) These signs have no brush marks or discrepancies, there are no mistakes, they are perfect, but equally they are soulless. Orlebeke (2006) reminds us that such seamless; standardisation

4. Leading refers to the distance between the baseline of successive lines of type. The term originated in the days of handtypesetting, when thin strips of lead were inserted into the forms to increase the vertical distance between lines of type.

5. Kerning refers to adjusting the space between two letters. If letters in a typeface are spaced too uniformly, they make a pattern that doesn't look uniform enough. Gaps occur, for example, around letters whose forms angle outward or frame an open space $(\mathrm{W}, \mathrm{Y}, \mathrm{V}, \mathrm{T})$.

6. The name Otara honours a mythological figure named Tara from Te Akitai traditions. In the 1950s Otara was still largely a rural area. However, it was then chosen as the location for a large State housing development and the influx of manual workers from Pasifica Islands such as Samo and Tonga. 
productions can lack a sense of authenticity and integrity. He says that the authenticity of handmade objects is what makes them valuable. It is their humanness that shines through, and this is the thing we so desperately crave... handmade objects are ultimately about direct and meaningful communication... it is the connection between people that we seek as designers, and it is through the use of our hands that we can make our work felt.” (p. 57)

Looking at these signs it has made me question how we display business signage and to whom is it directed. For instance, would the owner of an expensive new Mercedes Benz trust a company that displayed handwritten signage? I don't think he would. Equally the owner of the inexpensive car might feel a sense of ease and familiarity when encountering a sign that signified the personal and the local.

This opens up an interesting debate on how we view signage and the semiotics that have been embedded within them and indeed the value we place on hand crafted materials. Handwritten or hand crafted artefacts are seen more of a work of art and an affiliation to a skill that is no longer practiced. But these handcrafted works can only be associated with the arts, such galleries of trendy café's etc., and interestingly have no reliance or trust when taken out of the art and crafts area.

Ruskin (1857) said "It is not the material but the absence of human labour which makes things worthless”. (p. 45) When we look at the signage within Otara these cheap hand-produced signs act as advertising and as community symbols. They bear the rich marks and idiosyncrasies of local people talking typographically to their community. The signs are both words and images. They add reversed letter, spelling errors or strangely spaced words operate as a kind of vernacular irreverence. These are businesses speaking but on 'local' terms. Their marks of making are 'human' and explicit. Personality is not hidden but celebrated because the business is known as an identity rather than a franchised phenomenon.

\section{Conclusion}

The typographical examples displayed in these poorer areas such as Otara are more than shop or business signs, they are the soul of the area and seeing examples of these signs are extremely fascinating and rewarding and enriches our visual thinking, which opens up more questions than answers and can be the vehicle for a wealth of ideas. As designers we are always looking at textures, images, colours, space, type and it is examples like these that give inspiration for further design. It can be argued that designers do not criticize examples of these inexperienced people producing these signs, but more importantly they serve as catalysts for future design and have served as inspiration for many designs. A classic example of this can be seen in the famous typeface Future Black ${ }^{7}$, which was based on a crude handwritten street sign seen in a poor area of Spain. By analysing the community and the demographics within an area can have a big impact on the running of a business both in poor and affluent areas, get it wrong and it can have a huge impact on the running of a business and indeed the community. Typography is much deeper than a consideration of form and convention. When we design for communities, we need to understand the nuances of visual speech with which they communicate (Walker, 2000).

In the world of high-end corporate branding and slick marketing campaigns one has to ask, has design gone too far? Have we lost the sense of community and are we on the slippery slop to being a corporate branded commodity void of any individuality. Towns like Otara have been excluded from the investment of government or large corporate companies but in turn have maintained their close sense of community. It is interesting to note, what would happen if the buildings and signs where to be pulled down and new buildings in gleaming glass and aluminium with plastic neon glowing signs erected in its place with. What would happen to the soul of this town? Would it still have the close sense of community?

These examples of business signage are fast becoming a thing of the past and puts Otara in a unique position within the towns of New Zealand. On a worldwide scale Otara is not unique and similar examples of business signage can be seen in many places throughout the world, but they are dwindling as we are seeing the demise of the sign writer and the ever-increasing growth of the mighty corporate branding machine moving in. What has become interesting in researching into signage in poorer areas is that these examples of business signage has been produced out of necessity rather than design, and these idiosyncratic syncretic typographical examples can only exist where economic investment is absent.

7. Futura Black Designed by Josef Albers, 1926 Josef Albers drew this stencil sanserif form at the Bauhaus in 1926; Paul Renner and the Bauer design office made it into a typeface in 1929, and included it in the Futura series. First presented by the Bauer Type Foundry in 1928, Futura is commonly considered the major typeface development to come out of the Constructivist orientation of the Bauhaus movement in Germany. 


\section{REFERENCES}

Billings, Scott. "The Figure on the Side of the Road: Automobility and Cinematic Causality." http://www.scottbillings.com/pages/selected_writings/Figure-on-the-side-of-the-road-Scott_ Billings_2009.pdf.

Brewer, Chris. "Decaying Street Sign." http://www.iamchrisbrewer.com/2013/01/26/revisiting-picherthe-most-toxic-town-in-america/img_5300_v1_jpg/.

Clark, Nigel, and Claudia Bell. "Signifying Antipodality: From Imperial Monuments to Hyper-Rural Simulations." A Journal for Radical Perspectives 29, no. 25 (1994): 1-17.

Cox, Helen. Fading Ads of London. London: The History Press Ltd, 2014.

Fitzgerald, Scott. The Great Gatsby. New York: Charles Scribner’s Sons, 1925.

Ings, Welby. "Roadside Crosses: A Memorial and a Message." New Zealand Geographic 5A (2001): 55-57.

Jump, Frank. Fading Ads of New York City. New York: The History Press, 2001.

Kepes, Gyorgy. Language of Vision. Chicago: Theobalb, 1994.

Levine, Faythe, and Sam Macon. Sign Painters. New York: Princeton Architectural Press, 2012.

Loo, Van. The Crypt: In Beauty in Decay, (Second Edition). London: Carpet Bombing Culture, 2011.

Olney, James. Memory \& Narrative: The Weave of Life Writing. Chicago: University of Chicago Press, 1998.

Orlebeke, Clfton. "The Exquisite Connection." In Fingerprint: The Art of Using Handmade Elements in Graphic Design., edited by In Chen Design Associates, 56-57. Cincinnati: How Books, 2006.

Romany, Warren. Beauty in Decay II. London: Carpet Bombing Culture, 2012.

Ruscha, Ed. Fifty Years of Painting. New York: Distributed Art Publishers, 2010.

Ruskin, John. The Seven Lamps of Architecture. New York: Wiley \& Halsted, 1857.

Salen, Kate. "Surrogate Multiplicities: Typography in the Age of Invisibility." 35, no. 2 (2001): $132-$ 53.

Shells, Jay. http://jayshells.com/street.html.

Varisco, Tom. Signs of New Orleans. New Orleans: Tom Varisco Designs, 2008.

Walker, Susan. Typography and Language in Everyday Life: Prescriptions and Practices. . London: Longman, 2000.

\section{ABOUT THE AUTHOR}

David Sinfield: Has worked in the field of graphic design for over twenty-five years both nationally 
and internationally. He is a senior lecturer and teaches Graphic Design on the undergraduate and postgraduate programmes at Auckland University of Technology a present. As a graphic designer his research is located in the areas of narrative inquiry and social commentary. He publishes in a range of locations. In doing so, he moves graphic design discourse into the realm of linguistics, urban geography, unionism and broader discourse surrounding the image. His research explores issues surrounding serigraphic and animated narratives of underpaid workers, (portrayed mainly through typography). 